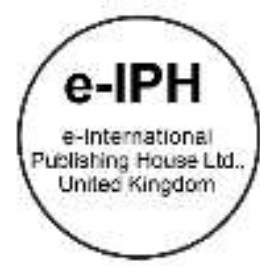

\title{
Re-Evaluating the International Tourists' Experience of Local Malaysian Food: What made them come back for a second taste?
}

\author{
Mazni Saad ${ }^{1}$, Nadhirah Abdul Rahman², Muhammad Fikri Umadi² \\ ${ }^{1}$ Kulliyah of Languages and Management, \\ International Islamic University Malaysia, Pagoh Education Hub, KM1, Jalan Panchor, 84600 Pagoh, Muar, Malaysia \\ 2School of Hospitality \& Creative Arts, \\ Management \& Science University, University Drive, Off Persiaran Olahraga, 40100 Shah Alam, Malaysia \\ maznisaad@iium.edu.my, nadhdo@gmail.com, Fikri.umadi@gmail.com \\ Tel: +60178787543
}

\begin{abstract}
Malaysia is popular among gastronomy tourists where many of international travellers visit the country-besides other reasons-to try a diverse range of food offered by the multi-ethnic food vendors. About $17 \%$ of 26.76 million tourist arrivals in 2016 spent on food. The focus of this study is to get an insight into the tourists' experience and evaluate the elements of experience that would lead to their revisit to the local food vendors. The study of purchase intention, aimed as a measure of the potential return visit of international tourists to the country, could benefit the tourism industry and the country's foreign exchange.
\end{abstract}

Keywords: Environmental Factors; Gastronomy Tourism; Malaysian Local Food, Purchase Intention

eISSN: 2398-4287 @ 2018. The Authors. Published for AMER ABRA cE-Bs by e-International Publishing House, Ltd., UK. This is an open-access article under the CC BYNC-ND license (http://creativecommons.org/licenses/by-nc-nd/4.0/). Peer-review under responsibility of AMER (Association of Malaysian Environment-Behaviour Researchers), ABRA (Association of Behavioural Researchers on Asians) and cE-Bs (Centre for Environment-Behaviour Studies), Faculty of Architecture, Planning \& Surveying, Universiti Teknologi MARA, Malaysia.

https://doi.org/10.21834/e-bpj.v3i9.1427

\subsection{Introduction}

Tourism is the second largest source of foreign exchange that contributes to the growth of the Malaysian economy (Bhuiyan, Siwar, \& Ismail, 2013). In 2016, the number of tourist arrivals in Malaysia reached 26.76 million (Tourism Malaysia, 2016), with gastronomy tourism - a tourism product - contributing to about $16.8 \%$ of the total income and coming second after the retail trade (shopping). From observation, tourists travel to Malaysia to experience the taste of the local food. However, there is very little clarity on how tourists view and value of local food, as well as how their experience affects the purchase intention. This research, therefore, aims to identify the tourists' experience and their purchase intention of local Malaysian food. Also, we examined the tourists' ratings on the characteristics of local food including the image, taste, smell, freshness and varieties. Besides, we evaluated the tourists' views on the environmental factors surrounding the food court and restaurants.

To date, the food tourism emerged and received an excellent response from leading countries' tourism product offerings. Gastronomy tourism is among the fastest growing and popular products. World Tourism Organization reported that gastronomy comprises $30 \%$ of the tourism revenues, and about $90 \%$ of those involved in tourism activities prioritised the eating and drinking matters while travelling (UNWTO, 2012). The properties or characteristics of the food products in the gastronomic services increase the image and identity of a country during their visit (Okumus, Okumus, \& Mckercher, 2007). Hence, the gastronomy tourism has become significant in the tourism industry.

The problem about the gastronomy in Malaysia, little information is available about the international tourists' perceptions of the local food scene, and whether their views contribute to the purchase intention of the local food products. Firstly, we are not sure if they like

eISSN: 2398-4287 ( 2018. The Authors. Published for AMER ABRA cE-Bs by e-International Publishing House, Ltd., UK. This is an open access article under the CC BYNC-ND license (http://creativecommons.org/licenses/by-nc-nd/4.0/). Peer-review under responsibility of AMER (Association of Malaysian Environment-Behaviour Researchers), ABRA (Association of Behavioural Researchers on Asians) and cE-Bs (Centre for Environment-Behaviour Studies), Faculty of Architecture, Planning \& Surveying, Universiti Teknologi MARA, Malaysia.

https://doi.org/10.21834/e-bpj.v3i9.1427 
the local food, and secondly, we are not sure what feature of the food affects their purchase intention. Nevertheless, the tourists may already have an image of the local food formed by the advertisements, social media and also by word of mouth. Therefore, two-fold research objectives are formulated to determine the tourists' level of experience of the local food. They are: (1) to examine the characteristics of local food based on the tourist's experience and preference and (2) to examine the environmental factors that lead to the tourist's experience of local food.

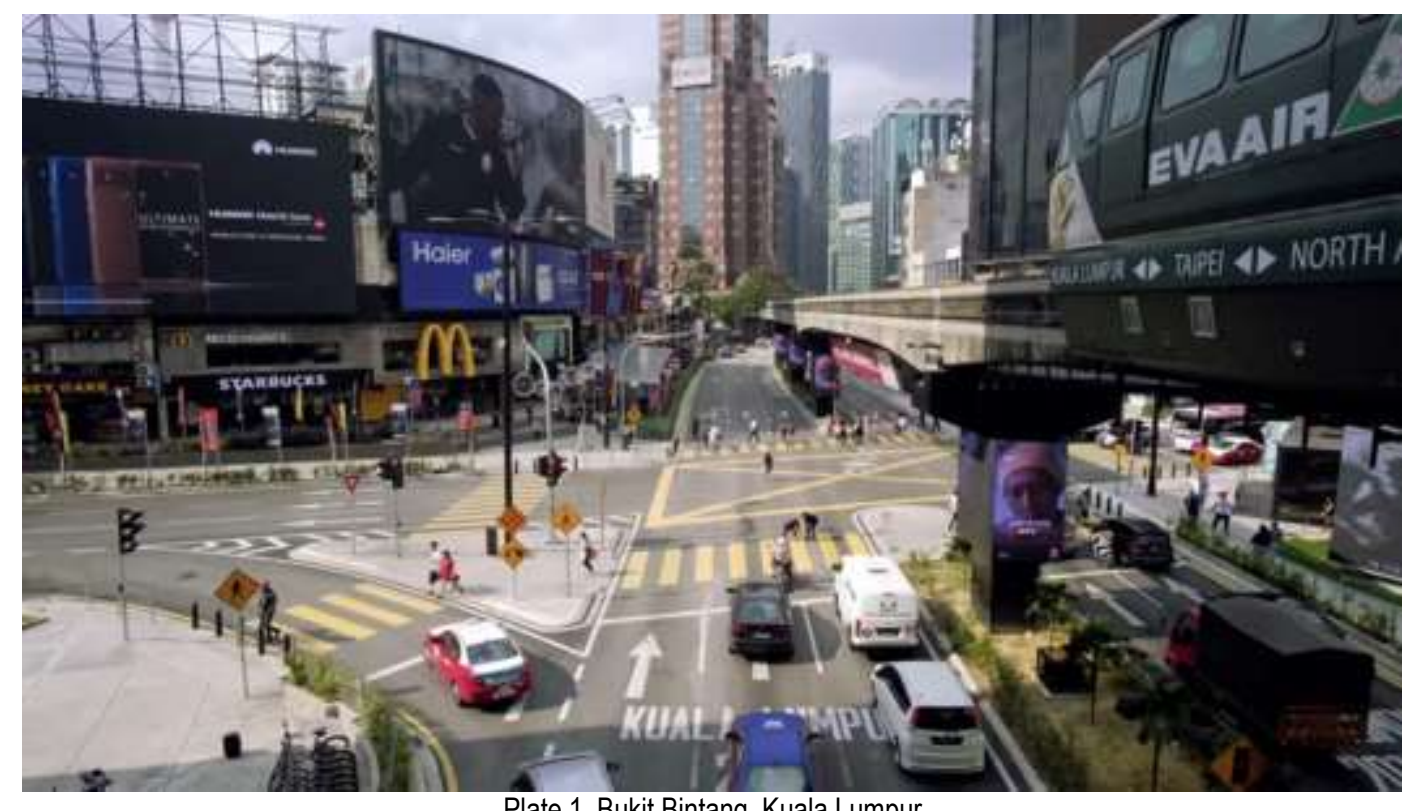

Plate 1. Bukit Bintang, Kuala Lumpur

\subsection{Literature Review}

\subsection{Characteristics of Local Food}

Food characteristics refer to the external factors of the food such as appearance as in the shape, colour, size, and consistency. According to Omar, Karim, and Omar (2015), characteristics of the local Malaysian food can affect a tourist's purchase intention. Tourists usually get an idea of a country's local food from advertisements, social media and also word of mouth, generally from other tourists.

The study of indigenous food by Moginon et al. (2012) shows that tourists enjoy the experience of tasting local food as it serves as a unique attraction and introduction to the local food culture experience. Indigenous food refers to the traditional or regional cuisine. Moginon et al.'s study emphasised the importance of taste. In later qualitative research, Saad, Abdullah, Adil, and Salleh (2015) revealed that lack of flavour and variety create persistent grumbles among the consumers even though it fulfilled the aim of the dietary set by the Ministry of Health in Malaysia.

The cognitive image seems to have a stronger influence than the effective image on the preferences for food destination and intention to eat the food (Seo, Yun, \& Kim, 2017). Besides, the preference for the food destination is said to predict an intention to eat the food. If this were the case, the cognitive image of destination food should, therefore, be identified and strengthened to increase the tourists' intention of eating destination food.

Ling, Karim, Othman, and Ramachandran (2010) found that when tourists dine in Malaysia, especially at the hawker stalls and night markets, they could see and taste a wide range of local cuisines. Besides experiencing these local flavours, the food at the stalls are also affordable for the tourists. It can be summarised here that the food characteristics can determine a consumer's acceptance of the food which can then lead to a desire to buy the food at some point and perhaps even confirming a perception of the food formulated earlier.

\subsection{Environmental Factors}

In general, environmental factors can be classified into two: eating and food environment. The implications of the environmental factors consisting the social, physical, and temporal characteristics of dining halls were investigated among children's eating behaviours by Moore, Murphy, Tapper, and Moore (2010). For an eating experience, Moore et al. (2010) argued that the environmental factors are essential. Based on 83 primary schools, the students made food choices and consumed the food for the eating behaviour was encouraged by the situation of the physical environments. Décor or crockery and adequate staffing were regarded as crucial environmental factors to contribute to the eating experience. Also, the seats, tables, plates, and cutlery were perceived as convenient eatery utensils and furniture.

A study of the environmental factor effects on the consumers' attitude towards the food they purchase distributed 10,000 questionnaires to a random sample of New Zealanders aged over 18 (Mirosa \& Lawson, 2012). The environment in this research is 
referred to the relaxing atmosphere and emphasised personal service. The results showed different findings between local and nonlocal food buyers. The local buyers were more interested in the fresh and non-processed foods, and ate fewer of the convenience and snack items. In contrast, the non-local buyers opted for fast food for lunches and dinners. The study concluded that local buyers were more liberal, environmentally and socially concerned than non-local buyers. The non-local buyers expressed that they did not enjoy shopping for food. Thus, Mirosa and Lawson (2012) suggested the marketers emphasise the personal value of eating local food to be the most effective persuasion strategy.

Food safety issues are part of environmental factors which through a simple swab experiment, Saad, See, Abdullah, and Nor (2018) demonstrated, can inverse a perceived knowledge of food hygiene. Food handlers often believe they have sufficient knowledge of food hygiene practices, but often this knowledge is not reflected in actual practices, for example, the hygienic cleaning of utensils. A lack of knowledge of food hygiene may jeopardise the customers' intention of buying local food. Therefore, it can be said that the environmental factors of food consumption can be based on the portion size, atmospherics, eating effort, eating with others and also eating distractions. Not to mention that the food shopping behaviour and socio-economic factors also contribute to the environmental factors of food consumption.

\subsection{Purchase Intention}

There has been an increase in interests in understanding a customer's purchase intention. In general, the purchase intention could be interpreted as the customer's willingness to buy a particular product or a specific service. Several external and internal factors can affect the purchase intentions. Studies show that customers evaluate the product before purchasing. Awan, Siddiquei, and Haider (2015) argued various factors affect the purchase intention of a customer, and mostly, the intention is influenced by marketing and branding practices. This study emphasises the products' quality features and health value including its nutrients to be the target for the marketers as it is part of the behavioural aspects that guide the customers to purchase the products.

A recent study on tourists' preferences in food selection in Malaysia found that tourists' behaviour and perception had a positive and significant impact on the intention of purchasing local food (Rahman, Zaman, Hassan, \& Wei, 2018). The study suggests the managers and policymakers strengthen the restaurants' competitive position by identifying and understanding of tourists' behaviour and also assessing the tourists' acceptability in local foods. The presented literature demonstrates that evidence of the consumer demand for local food has risen, so as the study for the factors that are affecting the purchase intentions.

\subsection{Characteristics of Local Food and Purchase Intention}

Previous researchers like Caber, Yilmaz, Kilicarslan, and Ozturk (2018), Brečić, Mesić, and Cerjak, (2017), Choi and Zhao (2014), and Moginon et al. (2012) have linked the characteristics of local food to consumers' purchase intention. An investigation on the role of tour guides giving the information or assisting tourists with food decision and on local food consumption was conducted in Turkey. Caber et al. (2018), surveyed the international tourists visiting Antalya, found that tour guide performance was the insignificant effect on food neophobia, while tourists' food involvement had a negative impact and decreased neophobia. Well-educated in gastronomic culture supported by an appealing-designed menu in local restaurants can motivate the international tourists to consume local food. Hence, the tour guides need to be knowledgeable about the world culinary culture so that they can explain professionally which can determine tourists' local food consumption. Besides, knowledge of the food characteristics is important to understand tourists' preferences of the food.

Brečić, Mesić, and Cerjak, (2017) examined the importance of quality food from the perspective of intrinsic and extrinsic in searching the consumers' motives in food choices among Croatian consumers. Evidences from the findings revealed that consumers were generally very concerned about intrinsic food characteristics. Healthy and tasty food lovers looked highly into the food characteristics, especially, taste, natural contents, calories and fat contents, and easy preparation is the determinants of intrinsic motives. As for the extrinsic attributes, the convenience consumers cared for the value for money, availability in shops and supermarket, and the price of the food. The consumption behaviour influenced by characteristics of food was identified as key determinants in deciding the implementation and effectiveness of health promotion strategies.

Choi and Zhao (2014) surveyed respondents' consideration of their lifestyle and restaurant attributes in dining out healthy meals at a restaurant. The test for 286 usable data showed $40 \%$ of the model of health-conscious lifestyle has significantly accounted for the variance in intentions. Educational level showed significance between university and graduate school in determining calories when ordering food at restaurants. The study suggested that consumers are interested in dining in a restaurant which offers healthy meals on the menus.

\subsection{Environmental Factors and Purchase Intention}

Several findings have demonstrated that environmental factors established a positive connection to consumer purchase intention. Ryu, Lee, Gon, and Kim (2012) stated their results that the quality of the physical environment is significant to the customer's perceived value and acts as a determinant to consumer satisfaction thus leading to their purchase intention. Similarly, consumer purchase intention was found significant to the customer's involvement in the restaurant, meaning that their experience also points to purchase intention (Lu \& Chi, 2018). Han and Hyun (2017) also found out that the quality of the physical environment could increase consumer satisfaction, and together with the restaurant's background music, it is said that it gives off a better consumer perception and also purchase intention. The positive effect of the restaurant's background music indicates that consumers are prepared to spend money on their main meal (Wilson, 2003). 
Veeck et al. (2014) studied major influences of the food choice effect among urban Chinese teenagers. The results from intensive depth interview with 16 family pairs revealed when it involves with meals outside campus, a distance for getting the meals has become one of the environmental interventions to the purchase intentions. Hectic schedules caused the preference of purchasing food from someone who can deliver food direct at the entrance of campuses. However, the survey also indicated that the teenagers were conscious of the food safety when the food was purchased. However, the sample was small and only from one city. The effect of environmental concerns significantly predicted consumer purchase intention for the respondent, thus motivated this research to look into the empirical results that it relates to purchasing intention in any significant way.

The theoretical framework in Figure 2.1 shows the relationships between Characteristics of Local Malaysian Food, Environmental Factor, and Purchase Intention. The earlier discussion provided evidence that intention to buy encounters many aspects and viewpoints from the consumers, but when factors such as characteristics of local food and environmental factors are satisfied, tourists could have a more transparent and more positive view of food they wish to purchase. The research examined the international tourists and their purchase intentions of local food as the following hypotheses: (H1): Satisfied Characteristics of Local Malaysian Food have a positive impact on the Purchase Intention and (H2): Satisfied Environmental Factors have a positive impact on the Purchase Intention.

\section{Independent Variables $\quad$ Dependent Variable}

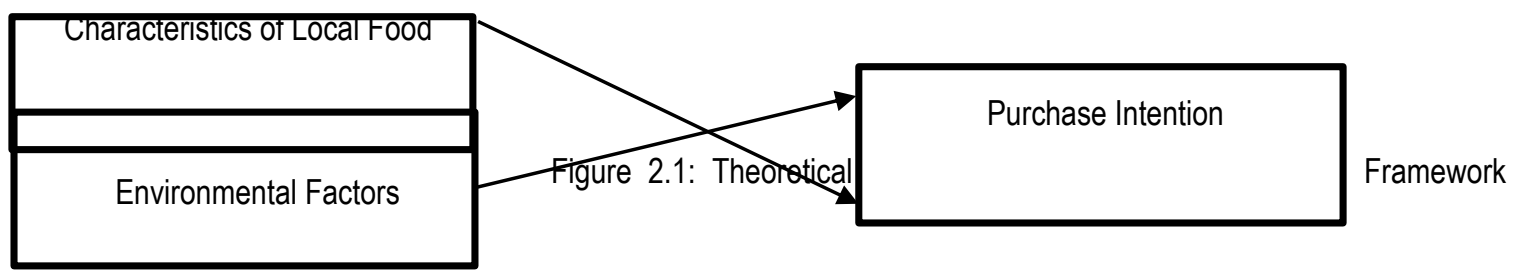

\subsection{Methodology}

The quantitative research method was employed at a cross-sectional level to test the hypothesis of the research and to investigate the relationship between the variables. The questionnaire survey was chosen as the best method of collecting data from a captive population of international tourists at a major tourist spot in Kuala Lumpur as it was a quick way of getting respondents to complete the questionnaire without any direct assistance or intervention from the researcher. The foreign tourists visiting Bukit Bintang in Kuala Lumpur were chosen as the target population because Bukit Bintang is not only well regarded as a remarkable hospitality experience, but is also the trendiest shopping and entertainment district of Kuala Lumpur, which offers everything that international tourists want. Directly administering the questionnaire to a group of people assembled at a particular place for a specific purpose was advantageous as it not only ensured a higher response rate but it was also carried out at a minimal cost (Dörnyei \& Taguchi, 2009). The questionnaire applied a six-point Likert scale with indicators from "1," "strongly agree" to "6," "strongly disagree." Question items for Characteristics of local Malaysian food and environmental factors were adopted from Jalis et al. (2009). Question items for purchase intention were adopted from Chavarria and Phakdeeauksorn (2017), Jalis et al. (2009), and Ling et al. (2010). Adaptations were made to the adopted items to suit this research.

\subsection{Findings}

\subsection{Sample Profile}

The survey achieved $100 \%$ of response rate with a total target collection of 202 respondents comprising international tourists at Bukit Bintang. Respondents' background tapped in this study was gender, age, occupation and country of origin. We also asked about their length of stay in Malaysia, the purpose of visiting Malaysia, the type of food that they tried and the type of food preferred. The profile showed that $54 \%$ of the respondents were male and the rest (46\%) were female. About $7 \%$ of the respondents were below 18 years old, $53.5 \%$ were in the range of 21 to 30 years old, $21.8 \%$ were between 31 and 40 years old, $8.4 \%$ were 41 to 50 years old, and $8.9 \%$ were above 51 years old.

\subsection{Assessment of Relationship Analysis}

A bivariate correlation was undertaken between study variables. The finding shows Characteristics of Local Food and Environmental Factor was significantly correlated at $r=.539, p<0.001$. The correlation coefficient output confirms the results of the scatter dot in that a significant positive relationship exists for the dependent variable; the Purchase Intention, and independent variables; Characteristics of Local Food $(r=.534, p<0.001)$ and Environmental Factor $(r=.498, p>0.001)$. Results of the correlation indicate that higher scores for both Characteristics of Local Food and Environmental Factor are associated with higher Purchase Intention.

Before analysing the data, each study variables were checked on the internal consistency. The Cronbach's Alpha rule of thumb was met, reaching .769 (five items) for Characteristics of Local Food (five items) and .675 (six items) for Environmental Factor. To test the hypotheses, this study computed a regression analysis to examine the relationships between Characteristics of Local Food and Environmental Factors towards Purchase Intention of the tourists. As shown in Table 1 \& Table 2, Characteristics of Local Food (B = $0.384, t=5.521, p<.001)$ and Environmental Factors $(B=0.290, t=4.344, p<.001)$ showed significant effects on Purchase Intention. 
It can be summarised that if the average level of both Characteristics of Local Food and Environmental Factors were high, the average level of Purchase Intention would also be high. Overall, the variance explained by the two predictors was $34.8 \%\left(\mathrm{R}^{2}\right.$ adjusted $\left.=.341\right)$ in Purchase Intention among the tourists.

Table 1: Summary of regression analysis

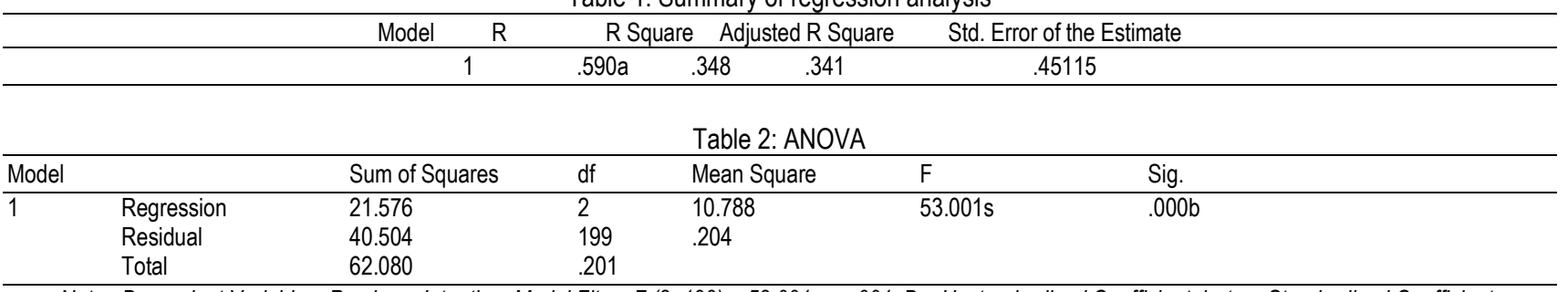

Note: Dependent Variable $=$ Purchase Intention; Model Fits $=F(2,199)=53.001, p<.001 ; B=$ Unstandardized Coefficient; beta $=$ Standardized Coefficient;

$$
{ }^{* * *} p<.001
$$

Concerning the model evaluation, the regression model fit the data since the ANOVA test was significant $(F(2,199)=53.001, p$ $<.001)$. Besides, based on Figure 3.1, the Normal Probability plot also indicated that the model's residual value was normally distributed as the majority of the observed values (small dots) were on the straight line. By looking at the scatter plot of the standardised residual value against the standardised predicted value, the pattern of the graph was random. As such, both hypotheses were confirmed as characteristics of Local Food, and Purchase Intention had a positive effect and is significant and Environmental Factors, and Purchase Intention had a positive effect and was significant.
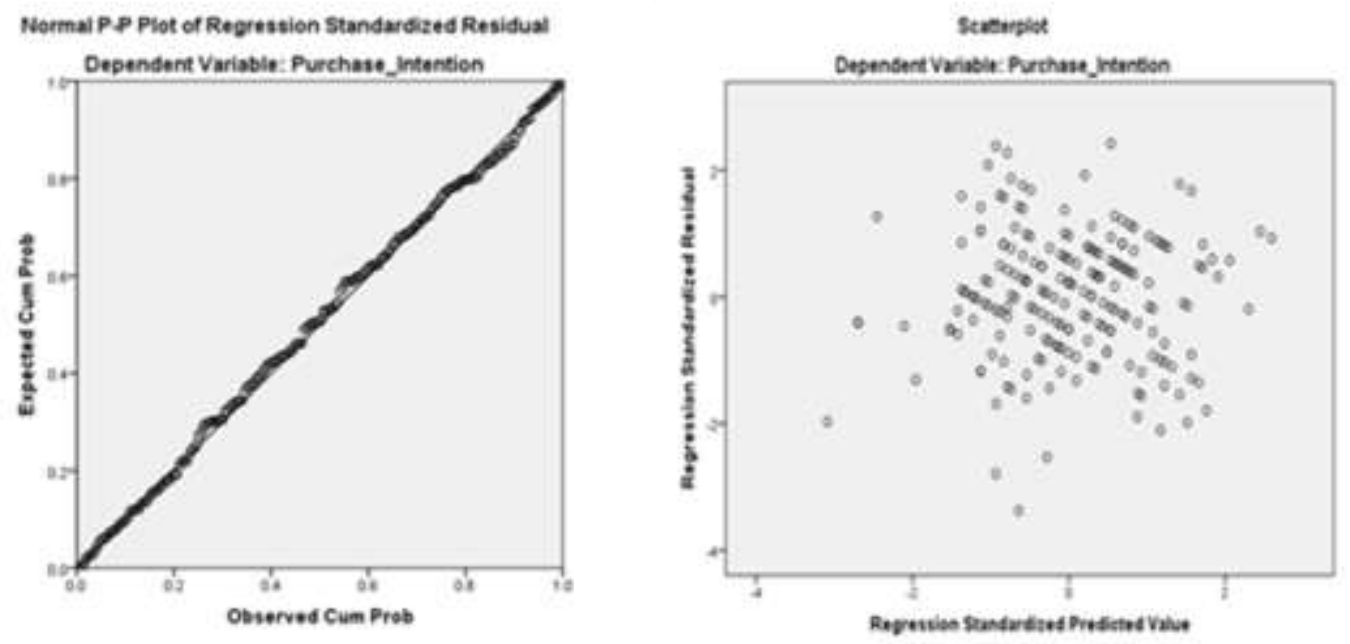

Figure 3.1 (a) The normality probability plot of standardized regression residual value and (b) scatter plot of standardized regression

\subsection{Discussions}

The empirical findings of the current study are very significant for the tourism industry. Food is a tourism product indispensable for the tourists' daily activities, which comprising major expenses for a visited destination. This research supports that characteristics of local Malaysian food and environmental factors are the important factors contributing towards a tourist's purchase intention. Despite the consistency with Caber et al. (2018), Brečić, Mesić, and Cerjak, (2017), Choi and Zhao (2012), Moginon et al. (2012), this research is very unique as the analysis of the survey provided empirical evidence about the effects of the local Malaysian food and its characteristics on tourists' purchase intention. Although the Malaysian local cuisine is often hot and spicy and very much influenced by surrounded Asian favours, the food was rated acceptable by tourists from different countries.

The finding of this research through open-ended questions also highlights on the tourist's confusion on the authenticity of local Malaysian food especially when a comparison of the local food is made with a few other Asian countries like Thailand, India and Indonesia. To minimise confusion, it is recommended that the travellers are exposed to the unique image of Malaysia as the melting pot of Asia whereby a variety of food represents a mixture of culture. Also for the convenience of tourists, there should be more information centres that provide brochures about Malaysian food and food destinations. Hotels and airports could also take an active role in promoting the Malaysian food image by providing information about local food and food destinations in the country. Also, marketing strategies should present both the authenticity and the unique cognitive image of local Malaysian food, as well as encourage tourists to experience local foods and gain internal information. 
Environmental factors also influence the tourist's purchase intention. Malaysian food culture and eating manners received the most comments in the open-ended questions. Therefore, improving the environment of local restaurants and stalls together with its food quality will only positively increase the tourists' perceptions that will lead to their purchase intention. The positive effect the environmental factors on the food purchase intention of this study in line with Ryu et al. (2012), Lu and chi (2018), Han and Hyun (2017), and Veeck et al. (2014). Consequently, this will then result in the tourists buy the local food rather than fast food. So, the economy of the local food vendors can be increased and also increase the interests of international tourists on the local food.

Theoretically, these tourists are attracted to the rich flavour, the spiciness and also the variety of the local food; thus for many tourists, this is a reason to travel to Malaysia. Moreover, the cultural diversity and the food bazaars in Malaysia are seen as unique to the country, thus influencing their behaviour towards experiencing it themselves. Practically, many aspects of this research's findings are beneficial. Gastronomy tourism is one tourism product that contributes to the growth of the country's economy. A good evaluation from the international tourists could only be positive for the image of local food and could result in higher tourist arrivals that would help improve the country's economy.

\subsection{Conclusion and Recommendations}

It is undeniable that Malaysia plays a vital role in the map of world culinary tourism. The fusion of cuisines offered by a multicultural population made Malaysian food unique. The speciality of Malaysian gastronomy has successfully influenced tourists to spend on local food. To stimulate the income growth in the gastronomy industry-especially those located at famous tourism destination, such as Bukit Bintang-this study recommends that local restaurants improve the presentation of the local food to the international tourists. Besides, restaurants can also offer more varieties of local food for dinner options. More effort is needed to keep to the originality of the food; from the taste to the ingredients, its preparation as well as the presentation to the tourists. The findings of this research extend its suggestion to the restaurants to include a more customer friendly menu with lesser types of cuisines offered (e.g., Western, Thai, Indonesian). The many different choices may confuse the tourists. This suggestion could be strengthening by the involvement of local authorities by campaigning about the importance of introducing and highlighting the local food at tourist destinations. Furthermore, it is recommended that the local food sold at Bukit Bintang restaurants be improved regarding its variety of local dishes since when Bukit Bintang has become a significant eating place at night. The local restaurant owners are also advised to provide kueh or local snacks as a dessert or light food as a way to introduce more local food at night selling. Selling nasi campur (scoop of white rice accompanied by various small portions of side dishes like vegetables, meats, eggs, etc.), for instance, should be continued at night, to balance other types of restaurants like the mamak style (various food often sold by Tamil Muslims), tom yam (spicy soup originated from Thailand), nasi Arab (traditional dish from Middle East countries that contains of rice, meal, and spices), and western food.

Besides the interesting findings, this research faced some limitations in data collection with Middle Eastern tourists. They refused to speak English, and as a result, most of the participation came from the Western tourists. In a future study, the questionnaire survey may include the Arabic language as the observations found that Middle Eastern tourists are as many as or may be more than the Western tourists. However, this study can serve as the groundwork for research on the local food and for future research that explores further elements of local food purchase intention among tourist visit. Future studies should also investigate other factors that could contribute to the tourists' willingness to purchase and taste local Malaysian food. With this purpose in mind, researchers will need to consider expanding the survey to several other tourists' destinations that are related to gastronomy tourism to gain new knowledge and perspectives.

Nevertheless, through the lens of the world, Malaysia is now one of Asia's associated culinary tourism destinations. Its different local delicacies have become a significant tourist attraction, where every tourist who comes to Malaysia can only claim to have visited the country just after having tried the local food. A considerable amount of planning for tourism development in Malaysia would add more to create a friendly destination for all types tourists as stated in the KL Structure Plan 2020 would become to realizations with excellent facilities, high-tech infrastructure services, launching various international tourism programs, and actions.

\section{Acknowledgements}

The authors gratefully acknowledge the funding of this article through the 7th Asian Conference on Environment-Behaviour Studies National Taiwan University, Taipei, Taiwan, 09-10 April 2016 best paper award in the conference. The authors are also thankful to the Kulliyah of Languages and Management, International Islamic University Malaysia for the permission to attend the conference.

\section{References}

Awan, H. M., Siddiquei, A. N., and Haider, Z. (2015) Factors Affecting Halal Purchase Intention-Evidence from Pakistan's Halal Food Sector. Management Research Review, 38(6), 640-660

Bhuiyan, A. H., Siwar, C., \& Ismail, S. M. (2013). Tourism development in Malaysia from the perspective of development plans. Asian Social Science, 9(9), 11-18. DOI: 10.5539/ass.v9n9p11

Brečić, Mesić, and Cerjak, (2017). Importance of intrinsic and extrinsic quality food characteristics by different consumer segments, British Food Journal, 119(4):845 862 . 
Caber, M., Yilmaz,G., Kilicarslan, D., \& Ozturk, A. (2018). The effects of tour guide performance and food involvement on food neophobia and local food consumption intention. International Journal of Contemporary Hospitality Management, 30 (3), 1472-1491.

Choi, J. \& Zhao, J. (2014). Consumers' behaviors when eating out: Does eating out change consumers' intention to eat healthily? British Food Journal, 116 (3), 494-509, https://doi.org/10.1108/BFJ-06-2012-0136

Chavarria, L. C. T., \& Phakdee-auksorn, P. (2017). Understanding international tourists" attitudes towards street food in Phuket, Thailand. Tourism Management Perspectives, 21, 66-73.

Dörnyei \& Taguchi, 2009). Questionnaires in second language research: Construction, administration, and processing. Routledge

Han, H., \& Hyun, S. S. (2017). Impact of hotel-restaurant image and quality of physical-environment, service, and food on satisfaction and intention. International Journal of Hospitality Management, 63, 82-92.

Jalis, M. H., Zahari, M. S., Zulkifly, M. I., \& Othman, Z. (2009). Malaysian gastronomic tourism products: Assessing the level of their acceptance among the western tourists. South Asian Journal of Tourism and Heritage, 2(1), 31-44.

Ling, L. Q., Karim, M. S. A., Othman, M., Adzahan, N. M., \& Ramachandran, S. (2010). Relationships between Malaysian food image, tourist satisfaction, and behavioural intention. World Applied Sciences Journal, 10 (Tourism \& Hospitality), 164-171.

Lu, L., \& Chi, C. G. Q. (2018). Examining diners' decision-making of local food purchase: The role of menu stimuli and involvement. International Journal of Hospitality Management, 69, 113-123.

Mirosa, M. \& Lawson, R. (2012). Revealing the lifestyles. Lifestyles of Local Food Consumers. British Food Journal, 114(6): 816-825

Moginon, D.F., See, T.P., \& Saad, M. (2012). Indigenous food and destination marketing. Indigenous food and destination marketing. In Z. Artinah, M. R. Salleh, H. Rahmat, T. C. Chemah \& A. Rozita (Eds.), Current Issues in Hospitality and Tourism: Research and Innovations (pp. 355-358). Concorde Hotel, Kuala Lumpur Malaysia: Taylor \& Francis Group, London, UK (CRC Press/Balkema). https://books.google.com.my/books?id=cBMBgAAQBAJ\&pg=PA355\&dq=Indigenous+food+and+destination+marketing.\&hl=en\&sa=X\&ved=0ahUKEwip4LGj74vSAhUDuo8KHfNDAXkQ6AEIKTAA\#v=onepage $\& q=$ Indigenous $\% 20$ food $\% 20$ and $\% 20$ destination $\% 20$ marketing. \&f=false

Moore, S.N., Murphy, S.,Tapper, K., \& Moore, L. (2010). The social, physical and temporal characteristics of primary school dining halls and their implications for children's eating behaviours. Health Education, 110 (5), pp. 399-411. (doi:10.1108/09654281011068540)

Okumus, Okumus and Mckercher, 2007). Food Tourism as a Viable Market Segment: It's All How You Cook the Numbers! Journal of Travel \& Tourism Marketing, 25:2, 137-148

Omar, S. R., Ab Karim, S., \& Omar, S. N. (2015). Exploring international tourists' attitudes and perceptions: In characterizing Malaysian Heritage Food (MHF) as a tourism attraction in Malaysia. International Journal of Social Science and Humanity, 5(3), 321.

Rahman, M.S., Zaman, M.H., Hassan, H., \& Wei, C.C. (2018) "Tourist's preferences in selection of local food: perception and behavior embedded model", Tourism Review, https://doi.org/10.1108/TR-04-2017-0079

Ryu, K., Lee, H. R., \& Gon Kim, W. (2012). The influence of the quality of the physical environment, food, and service on restaurant image, customer perceived value, customer satisfaction, and behavioural intentions. International Journal of Contemporary Hospitality Management, 24(2), 200-223.

Saad, M., Abdullah, M.F.F., Adil, M.A.M., \& Salleh, M.F. (2015). Cooking up a Storm! Rising above Challenges in Regulated Food Standards. UPM International Journal of Economics and Management (IJEM), 9 (S), 135-154

Saad, M., See, T.P., Abdullah, M.F.F., Nor, N.M. (2018). Enhancing Regular Monitoring of Food-Contact Surface Hygiene with Rapid Microbial Kits, Asian Journal of Behavioural Studies. Vol. 3. No. 11 (2018)

Seo, S., Yun, N., \& Kim, O. Y. (2017). Destination food image and intention to eat destination foods: a view from Korea. Current Issues in Tourism, 20(2), 135-156.

Tourism Malaysia 2016 Annual Report (2016). https://www.tourism.gov.my/activities/view/tourism-malaysia-2016-annual-report

Veeck, A. V., Yu, F.G, Yu, H.Y, Veeck, G., Gentry, J.W. (2014). Influences on food choices of urban Chinese teenagers", Young Consumers, Vol. 15 Issue: 4 , pp.296311, https://doi.org/10.1108/YC-08-2013-00390

Wilson, S. (2003). The effect of music on perceived atmosphere and purchase intentions in a restaurant. Psychology of music, 31(1), 93-112.

World Tourism Organization UNWTO (2012). Annual Report 2012, published by the World Tourism Organization (UNWTO), Madrid, Spain, First printing 2013. Printed in Spain. cf.cdn.unwto.org/sites/all/files/pdf/annual_report_2012.pdf 